\title{
Identification of factors for a successful implementation of medication reviews in community pharmacies: Using Positive Deviance in pharmaceutical care
}

\author{
Isabell Waltering ${ }^{1}\left(\mathbb{D} \cdot\right.$ Oliver Schwalbe $^{2} \cdot$ Georg Hempel $^{1}(\mathbb{C}$
}

Received: 11 March 2021 / Accepted: 28 July 2021 / Published online: 6 August 2021

(c) The Author(s) 2021

\begin{abstract}
Background Pharmacists in community pharmacies worldwide successfully conduct an increasing number of medication reviews (MR). Since June 2012 MR are incorporated in the German ordinance on the operation of pharmacies as pharmaceutical service. In November 2014, a German guideline for MR was established. Different teaching programmes for MR were implemented since. Despite these favorable conditions, only few pharmacies conduct MR regularly. Objective: Identification of factors necessary for a successful implementation of MR in community pharmacies. Setting: Community pharmacies located in the area of the Pharmacists' Chamber Westphalia-Lippe (Part of Northrhine-Westphalia, Germany). Method: Following a Positive-Deviance approach, telephone interviews were conducted in community pharmacies with pharmacy-owners, MR-trained employed pharmacists, and technicians. Data evaluation was performed using qualitative content analysis. Main outcome results: Successful strategies for implementing MR in community pharmacies. Results: Forty-four interviews were conducted and analysed. Thirty-three success factors were identified. Data analysis revealed two groups of success-factors important for implementation of MR; organisational $(n=25)$ and individual factors $(n=8)$. Relevant organisational success-factor were involvement of the entire team with active involvement of technicians, documentation of results in the pharmacy software and training in patient-identification and communication. Restructuring of workflows increased time-periods for MR. Important individual success-factors were: motivation and identification with the service, routine in execution to enhance self-esteem, and specialisation in pharmacotherapy of particular diseases. Pharmacy-owners play a pivotal role as motivators. Professional healthcare attitude, exhibited in daily routine, leads to increased acceptance by patients and practitioners and thus increases implementation-rates considerably. Conclusion: We were able to define strategies for successful implementation of MR in community pharmacies.
\end{abstract}

Keywords Community pharmacy $\cdot$ Implementation $\cdot$ Medication review $\cdot$ Positive Deviance $\cdot$ Success factor

\section{Impact of practice}

- Positive Deviance is a unique approach in health services research to identify strategiesinternally generated rather than externally stipulated.

Isabell Waltering

i.waltering@uni-muenster.de

1 Institute of Pharmaceutical and Medicinal Chemistry, Clinical Pharmacy, Westfaelische Wilhelms-University Muenster, Corrensstrasse 48, 48149 Muenster, Germany

2 Department of Education and Training, Pharmacists' Chamber of Westphalia-Lippe, Bismarckallee 25, 48151 Muenster, Germany
- The identified success factors close the gap between barriers and facilitators for theimplementation of MR known from literature and procedures functioning already in real life.

- The different factors identified can be used by individual pharmacies to tailor measures for optimisation of MR provision.

- Involvement of the entire team and ongoing training of all team members in the differentaspects of MR are the most important organisational factors. Individual motivation and supportfrom pharmacy owners is of utmost importance to conduct MR successfully. 


\section{Introduction}

During the last decade, multi-morbidity, chronic illnesses and polymedication have increased, and are projected to increase further [1]. Therefore, numerous problems with medication therapy occur like non-adherence, over- and underprescribing, side-effects or drug-drug-interactions [2]. Medication reviews (MR) performed by community pharmacists can play a pivotal role in the management of these problems and are therefore already implemented as a cognitive service in several countries [3-7]. German pharmacies are facing a turning point with focusing on patient care by conducting MR rather than solely on dispensing.
A first step was the incorporation of MR in the German ordinance on the operation of pharmacies as a pharmaceutical service in 2012 to establish a legal basis for this service [8]. A guideline for conducting MR was published in 2014 by the federal pharmacy chamber [9]. To support pharmacists/pre-registration-students in performing MR, a six month teaching programme called Apo-AMTSprogramme (Fig. 1), has been implemented in WestphaliaLippe; a region in Germany; since 2012 to impart competence on how to conduct intermediate MR Type $2 \mathrm{a}$ in line with the Pharmaceutical Care Network Europe (PCNE) definition [10, 11]. Even if Apo-AMTS is implemented in Westphalia-Lippe the programme is open for all pharmacists or pre-registration students in Germany.

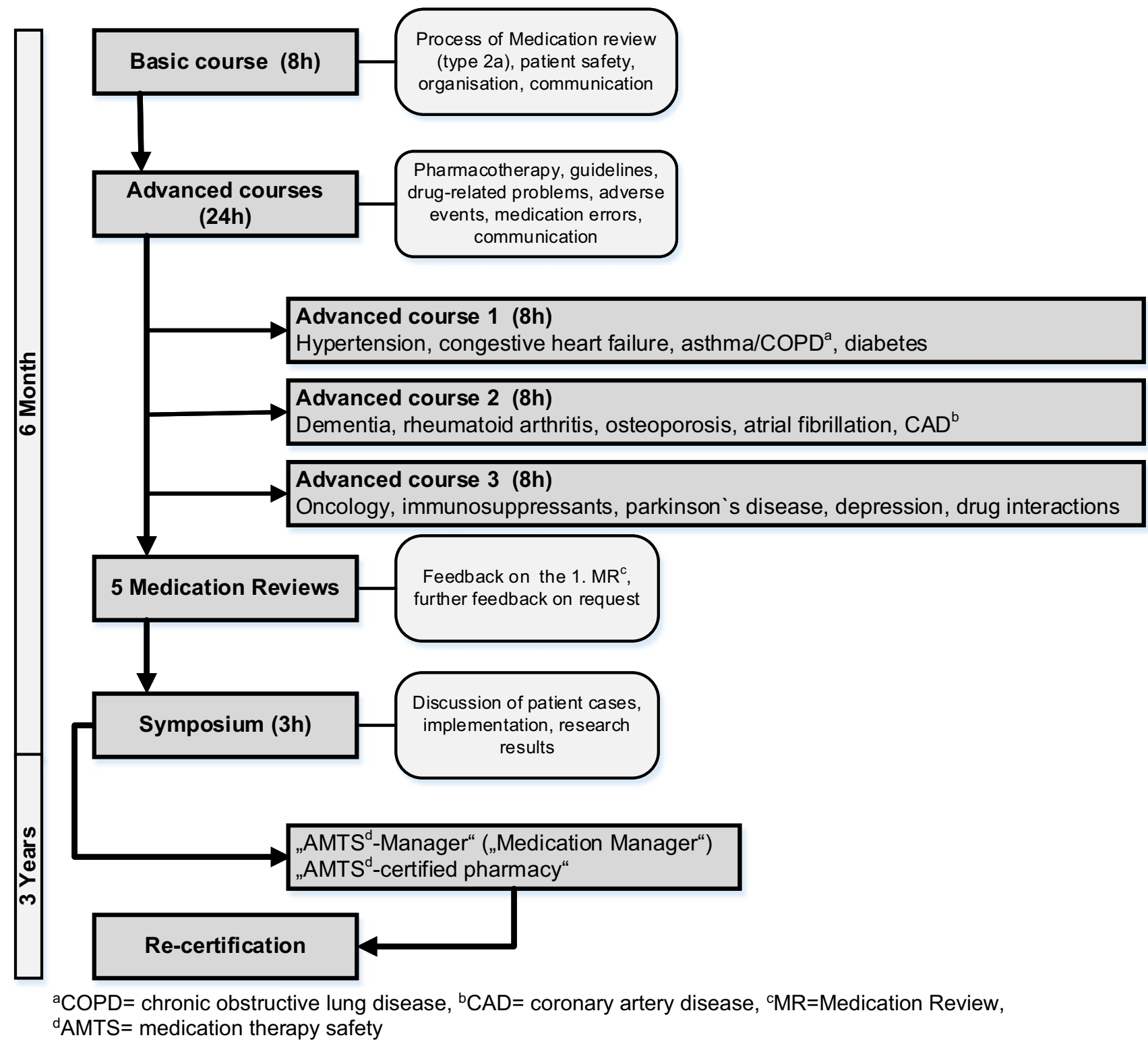

Fig. 1 Course of the Apo-AMTS-programme 
In addition to training, several tools (e.g., documentation material, promotion material, hotline for pharmacotherapeutic questions) were developed to support implementation. An online survey executed in June 2016 revealed that only 53 (33\%) of 163 certified pharmacies (AMTS-qualified pharmacies) conducted at least one MR per month, whereby $36 \%$ conducted no MR at all. Despite being trained and equipped with adequate material and having access to professional support, only a small number of pharmacies implemented this service for their patients on a regular basis. Facilitators and barriers to implement MR in community pharmacies like lack of time and staff, documentation of MR, hight demand of dispensing related activities were described in the literature previously, but they were derived from theory and formulated rather general and hence not applicable to German community pharmacies without modifications. It appears that little consideration has been given how facilitators like education and training for pharmacists, professional satisfaction and inclusion of technicians can best be used in practice to accelerate MR implementation and it seems important to identify facilitators at both individual and organisational level. We therefore used the Positive Deviance (PD) approach to assess practical measures already used successfully in a real life setting.

PD is an approach developed by Jerry and Monique Sternin,

based on observations that in every community or profession a team or individual person exists

that developed a more successful strategy or behavior compared to their peers, despite facing

the same barriers and challenges and having no extra or the same resources or knowledge

then their peers $[12,13]$.

Transfering PD to the disappointing situation with MR in trained pharmacies means that we included pharmacies conducting MR on a regular basis (high performer) to identify strategies and behaviors used in this group that have the potential to support the implementation of this service in all community pharmacies.

PD approaches were able to show impressive improvement in health-outcomes for complex problems globally (childhood nutrition, pregnancy outcomes, condom use) [14]. PD-studies are also frequently used in hospital settings e.g. to reduce the rates of nosocomial infections [15-18]. To the best of our knowledge, this is the first study applying PD to the community pharmacy sector in Europe.

\section{Aim of the study}

Our aim was to identify success factors for implementation of medication reviews in German community pharmacies using the Positive Deviance approach.

\section{Ethic approval}

According to the Fourth Act amending pharmaceutical legislation and other provisions, and the recommendations of the German Research Foundation for interview studies ethics approval are not necessary [19, 20]. The Clinical trial Regulation (Regulation EU No 536/2014) is actually nonapplicable in Germany [21].

\section{Methods}

\section{Study design}

We used the PD approach to detect specific measures and actions used in community pharmacies that were able to conduct MR on a regular basis and integrate this service into their routine. PD is based on the assumption that a group of persons, here the pharmacy teams with higher rates of $\mathrm{MR}$, act more successfully than their peers even though they use the same resources. Accordingly, same resources in our study are considered participation in a training-programme for pharmacists to conduct MR (Apo-AMTS) and access to all necessary material (e.g., documentation- and promotion-material) as well as professional support from the Pharmacists`Chamber Westphalia-Lippe. PD focusses on how procedures within the context of MR are transferred into practice instead of what is implemented. Therefore, this approach offers the unique opportunity to detect effective strategies compared to suggested measures from literature. To assure that these detected strategies are unique or at least exceptional, a control group (CG) was selected consisting of pharmacies not conducting MR despite being trained and equipped equally [14]. We performed the study from March 2017 until March 2019 in the area of the Pharmacists` Chamber of Westphalia-Lippe.

\section{Participants and recruitment}

Recruitment of the different pharmacies followed the purposive sampling method [22]. All eligible pharmacies were certified AMTS-pharmacies (see Fig. 1) $(\mathrm{N}=354)$ and additionally enrolled in a collaboration project with a health insurance company (3A-project). Within this project, pharmacies received $80 €$ for every documented MR. AMTSpharmacies enrolled in the 3A-project with the highest count of documented MR from December 2016 until March 2017 were selected for the PD-group as high-performers; enrolled pharmacies with no MR during this time frame were selected as control-group (CG). Inclusion criteria for the pharmacies in both groups was the engagement of at least one AMTSmanager (trained pharmacist with successful completion of the AMTS-programme) to assure an equal baseline situation 
according to organisational structures. To assess regional effects, pharmacies were additionally stratified by city-size and their geographical position within Westphalia-Lippe [23]. An AMTS-manager, a technician and the pharmacyowner/branch-manager from each pharmacy were invited for participation (professional groups). All participants received an information sheet including aim and structure of the study and a consent form for recording of the interviews. A sample size of six pharmacies for each group should be reached based on a recommendation of Rose et al. [24].

\section{Data collection}

For data collection we conducted semi-structured interviews. For this purpose, interview-guides for each professional group were developed and pilot-tested. Questions for the interview-guides were derived from literature and personal experience of IW (expertise in conducting MR and training in development of questionnaires). For this pilot-test, twelve interviews were performed with two interviewees in each professional group within both the PD-group and CG. A modification of the interview-guides followed this test mainly by rephrasing to perceive more questions that are open-ended. IW conducted all interviews. The interviewguides are available in Supplement 1. Audio recording was performed using Audacity ${ }^{\circledR}$ (Audacity Incorporation, Version 2.2.2). Interviews were de-identified (identification numbers for participants/pharmacies) and a verbatim transcript was created (f4transkript v6/f5transkript v3, Dresing $\&$ Pehl GmbH, Marburg). Additionally, age, gender and years of professional experience were documented for each participant and each participant provided written consent to recording and analysis of the data.

\section{Data analysis}

A qualitative content analysis based on Mayring et al. was performed [25]. A coding-system was developed, using a deductive-inductive approach. Therefore, based on the interview-guides, a first set of main codes was deviated and amended by sub-codes retrieved from the interview-transcripts. Two raters tested the coding-system independently. Besides IW as first rater, the second rater (OS) was a pharmacist experienced in qualitative studies and not involved in data collection and data analysis. Their results were assessed in a closed-loop process through modifications with subsequent revision and retesting until finalisation. Code-development and coding was performed using MAXQDA (Verbi Gmbh, Berlin, version 12). The complete coding-system is provided in Supplement 2.

For each main code the contents of the associated subcodes were paraphrased. These paraphrases were then summarised for the different professions in PD-group and CG.
Next, a synopsis was created for the conclusions from each main code separately for both groups. Supporting aspects for the implementation of MR were extracted from these summaries and phrased as success factors [25]. Conclusions mentioned in the PD-group and CG were rated as not relevant or unique because these strategies were mentioned in both groups but failed in the CG. Finally, the different success factors from the main codes were subsumed and doublings were removed. Hence, a final set of unique or important aspects and strategies to foster MR as a cognitive service in community pharmacies could be developed.

\section{Results}

In the 3A-project 301 certified pharmacies were enrolled, of which 171 (57\%) reached an average of $\bar{x} 4.7$ [range 1-14] documented MR. Twenty-two pharmacies (eleven per group) were included. Pharmacies in the PD-group conducted a minimum of five MR up to a maximum of 14 MR during the inclusion timeframe. Data saturation was reached after 44 interviews (24 PD-group, $20 \mathrm{CG}$ ). Table 1 shows the results of the recruitment process.

Interviews were conducted in German, hence the codings and quotations presented were translated into English with support of a native speaker aiming to reflect the true meaning as accurately as possible.

Five main codes emerged from the content analysis representing the important themes:

- Organisational aspects of medication reviews

- Execution of medication reviews

- Collaboration within the medication review process

- Personal attitude towards medication reviews

- Benefit of medication reviews for community pharmacies

\section{Organisational aspects of medication reviews}

This main code was defined as text passages describing organisational structures, prerequisites, and resources relevant for the execution of MR. Thirteen organisational aspects were identified. A complete list of all success factors is displayed in Supplement 3a, quotations to exemplify the development of the different codes are listed in Supplement 4. Involvement of the entire team of the pharmacy deemed most important. Team meetings should include education about the MR-process, roles of the different team-members, patient identification and recruitment, and benefit of MR. Additionally; ongoing education and specialisation of pharmacists in different diseases were emphasised. Participants of the CG did not mention any of these topics. 
Table 1 Characteristics of pharmacies and participants

\begin{tabular}{|c|c|c|c|}
\hline & & Positive Deviance-Group & Control-Group \\
\hline \multirow[t]{4}{*}{ Pharmacies $\mathrm{N}^{\mathrm{a}}$} & Total & 8 & 7 \\
\hline & Small town & 2 & 3 \\
\hline & Medium-size town & 4 & 3 \\
\hline & Large city & 2 & 1 \\
\hline \multirow[t]{5}{*}{ Professional group $\mathrm{N}^{\mathrm{a}}$} & Owner & 8 & 7 \\
\hline & AMTS-MA $^{\mathrm{b}}$ & 8 & 7 \\
\hline & Technician & 8 & 6 \\
\hline & ${ }^{\mathrm{a}} \mathrm{N}(\overline{\mathrm{x}})$ Pharm. staff & $\overline{\mathrm{x}} 14.5[5-14]$ & $\overline{\mathrm{x}} 11,1[5-24]$ \\
\hline & $\%(\overline{\mathrm{x}})$ Pharmacists & $\overline{\mathrm{x}} 33.6 \%[14 \%-60 \%]$ & $\begin{array}{l}\bar{x} 34.4 \%[18 \%- \\
50 \%]\end{array}$ \\
\hline Female, $\mathrm{N}^{\mathrm{a}}(\%)$ & & $20(83 \%)$ & $14(70 \%)$ \\
\hline \multirow[t]{3}{*}{ Female Professional group $\mathrm{N}^{\mathrm{a}}(\%)$} & Owner & $4(50 \%)$ & $2(29 \%)$ \\
\hline & AMTS-MA ${ }^{\mathrm{b}}$ & $8(100 \%)$ & $6(86 \%)$ \\
\hline & Technician & $8(100 \%)$ & $6(100 \%)$ \\
\hline \multirow[t]{3}{*}{ Age (years), mean, $\mathrm{SD}$, range } & Owner & $46.9 \pm 8.1[38-59]$ & $50.0 \pm 9.8[38-65]$ \\
\hline & AMTS-MA ${ }^{b}$ & $39.8 \pm 10.6[28-56]$ & $40.0 \pm 12.2[29-61]$ \\
\hline & Technician & $35.7 \pm 8.4[29-53]$ & $36.8 \pm 14.5[25-55]$ \\
\hline \multirow[t]{3}{*}{ Years in practice, mean, $\mathrm{SD}$, range } & Owner & $15.9 \pm 8.5[6-32]$ & $23.0 \pm 9.9[11-38]$ \\
\hline & AMTS-MA $^{\mathrm{b}}$ & $13.6 \pm 10.7[2-32]$ & $12.0 \pm 12.1[3-35]$ \\
\hline & Technician & $14.4 \pm 7.2[6-30]$ & $10.8 \pm 10.2[2-27]$ \\
\hline
\end{tabular}

SD Standard deviation, Pharm. Pharmaceutical

${ }^{\mathrm{a}} \mathrm{N}=$ Number

${ }^{\mathrm{b}}$ AMTS-Ma AMTS-manager

\section{Execution of medication reviews}

Text passages encoded within this main code referred to professional requirements and support used to conduct MR. Analysis resulted in ten success factors (Supplement 3b). Appropriate identification of eligible patients was rated crucial in the PD-group. Identification criteria were patients with polymedication, patients overwhelmed with their medication, and patients experiencing side-effects.

Most participants used more than one data source to conduct a MR, mainly the patient's medication list, whereupon the brown-bag (patient brings all her/his actually used medication) was considered the most important source of information about the current medication. Usage of clinicaldecision-support systems like the ABDA-database, available in all German pharmacies, is common. In addition, pharmacies in the PD-group used external resources like the drug-information-centre of the Pharmacists`Chamber in Westphalia-Lippe. Further important measures identified in the PD-group were information exchange within the entire pharmacy-team on patients receiving MR and giving feedback to technicians about patients identified by them. Documentation plays a pivotal role for implementation of MR. Optimally, specific documentation forms are adapted for the individual pharmacy and incorporated into the software making MR-results visible for all team-members.
Further relevant aspects were a need for more standardisation of this service and a change in personal attitude of each team-member towards MR, which must be recognised as meaningful and valuable for the patient and the pharmacy. Conducting MR also requires routine and self-esteem of the particular pharmacist.

\section{Collaboration within the medication review process}

Statements towards collaboration with patients/caregivers and practitioners were allocated to this main code. Practicioners involved in MR conducted in community pharmacies are usually general practitioners however; medical specialists are contacted during the MR process as well. Three sub-codes were developed during analysis revealing eleven success factors: General aspects $(\mathrm{N}=3)$, Collaboration with prescribers $(\mathrm{N}=5)$ and Collaboration with patients $(\mathrm{N}=3)$, (Suppl.3c). Members of the PD-group show their competencies on a daily basis e.g. with interaction- and plausibilitychecks which leads to a better visibility of pharmaceutical expertise, resulting in a better cooperation with prescribers, and higher acceptance as health-care professionals by patients and practitioners. Members of the PD-group had a positive attitude towards MR and demonstrated fewer difficulties in offering this service to patients and communicating with prescribers. Intensified collaboration with nursing 
homes (German pharmacies need a contract to provide medication for nursing homes) by offering MR to residents facilitated the implementation process of MR because nurses can carry out patient identification and information on the complete medication is available in the pharmacy. Both interview groups stated that remuneration through insurance companies, which is only the case in local projects in Germany, would support acceptance.

In general, participants in the PD-group mentioned good collaboration with the practitioners in contrast to members of the CG. Information of practitioners about MR, definition of tasks and establishing of communication-channels were mentioned as necessary before starting this service. Working in rural areas can possibly be an advantage for collaboration with practitioners but data was inconclusive.

The PD-group-members thought themselves as mediator between patient and practitioner whereby members of the CG regarded themselves as competitor or as helpmate of the practitioners reversely.

\section{Personal attitude towards medication reviews}

This code summarises statements, which describe how motives and personal engagement influence the implementation of MR. The synopsis of all statements and comparison of PD-group and CG resulted in eleven important factors (Suppl. 3d).

Participants of the PD-group showed a different attitude towards their patients/clients. The ratio of the frequency of the use of the terms patient and customer was 1.8 in the PDgroup compared to 3.5 in the CG. We identified a positive attitude towards MR as the main factor to support implementation of this service. This perception appeared in all three professional groups, and leads to increased professional satisfaction and enhances the attractiveness of the workingplace. In both interview-groups, support by the pharmacyowner/branch-manager was rated as very important whereby participants of the PD-group experienced this in a positive way (MR during working hours, new structures to offer this service, paid continuing education). Participants in the CG missed support or described themselves as lone warrior and MR as stressful. In the CG technicians showed interest in MR or conducted already small brown-bag-reviews. In contrast, AMTS-managers in the CG felt uncomfortable to take over responsibilities in the context of MR.

\section{Benefit of medication reviews for community pharmacies}

Passages that correlate with benefits of MR are subsumed in this code. Four success factors were identified (Suppl. 3e). The possibility to demonstrate professionalism in healthcare was the main benefit in the PD-group. This aspect was detectable in all professional groups, mainly in the group of pharmacy-owners. Pharmacy-owners and technicians in the CG did not mention this topic at all. Increased customer loyalty was mentioned in the CG as benefit. Some interviewees in the CG, mostly the trained pharmacists, did not see any benefit at all. Economic benefits were coded twice as often in the PD-group achieved through acquisition of new patrons, dispensing of more medication related to increased adherence and using MR as differentiation to online pharmacies. Remuneration of MR itself is not a successfactor. Pharmacies in the CG were eligible for payment in the 3A-project but did not conduct MR at all. Increased attraction of the working-place and motivation of personnel were discussed only in this group.

\section{Final set of success factors for the implementation of medication reviews}

All factors derived from the main codes were summarised and doublings eliminated. A summary of all success factors from each main code is provided in Supplement 5. Based on these results, we compiled a final set of 33 success factors (Table 2). The different factors were grouped in organisational (25) and individual factors (8).

\section{Discussion}

Until now, MR in Germany are not broadly implemented as a pharmaceutical practice service and mainly conducted within projects like the Apo-AMTS-programme. Positive Deviance is a unique approach in health service research. A distinctive feature is the focus on how things are done instead of what is done $[12,13]$. This design enabled us to derive factors for an effective implementation of MR in community pharmacies, which are internally generated (bottom-up) from successful participants, the so-called PD-group. Combining the PD-group with an additional CG, which is not a prerequisite for PD-studies, made it possible to sharpen the particular results and made it possible to extract a possible formular for success [14]. The included pharmacies were evenly distrubuted across Westphalia-Lippe and did not show relevant discrepancies according to demographics of the interviewees. Pharmacies in the CG had a smaller average number in pharmaceutical staff ( $\overline{\mathrm{x}} 11.1$ vs. $\overline{\mathrm{x}} 14.5)$ but a similar percentage of pharmacists ( $\bar{x} 34.4 \%$ vs. $\bar{x} 33.6 \%$ ). Therefore, these success factors can be considered as feasible within existing resources. Using our findings can lead to new strategies to foster the implementation of MR-services in community pharmacies on a larger scale, and to reevaluate and adjust existing measures and tools. The results strongly emphasise the involvement of the entire pharmacy-team and 
Table 2 Final set of success factors for the implementation of medication reviews in community pharmacies

Organisational Factors

Scope

Team

Involve the entire team of the pharmacy

Integrate technician actively in the $\mathrm{MR}^{\mathrm{a}}$ process esp. in acquisition of patients

Provide feedback to technicians for $\mathrm{MR}^{\mathrm{a}}$

Document the results visible for the entire team

Training, continuing education

Provide regular training sessions for all team members in process, patient identification and communication, and benefit of $\mathrm{MR}^{\mathrm{a}}$

Offer chances for ongoing education in pharmacotherapy

Acknowledge time for education as working hours

Personnel structure

Restructure workflow within the pharmacy team and allocate tasks according to competencies Incorporate time for $\mathrm{MR}^{\mathrm{a}}$ into the schedule, provide time as office-time

Execute $\mathrm{MR}^{\mathrm{a}}$ during working hours

Assure execution of reviews without interruption

Professionalisation of the service

Use standardised material for execution of $\mathrm{MR}^{\mathrm{a}}$ included in software

Equip pharmacy with additional databases and literature

Generate a template for written results for patients and prescribers

Develop a standard for the organisation of appointments

Patient acquisition

Define patient criteria for acquisition

Lable eligible patients in pharmacy software

Start providing $\mathrm{MR}^{\mathrm{a}}$ for patrons and/or nursing home residents

Collaboration

Inform practitioners personally prior to start $\mathrm{MR}^{\mathrm{a}}$

Define competencies and determine communication channels

Discuss first $\mathrm{MR}^{\mathrm{a}}$ face-to-face with practitioners

Organise regular meetings with practitioners

Advertisment

Use social media to communicate the service

Utilise branded promotion material

Communicate adequate with the different target groups

Individual Factors

Be ready to overtake responsibility

Show a positive attitude towards $\mathrm{MR}^{\mathrm{a}}$

Demonstrate pharmaceutical competencies in daily routine

Specialise in specific topics (disease states/medication classes)

Enhance skills in patient communication

Execute $\mathrm{MR}^{\mathrm{a}}$ for training purpose to increase routine

Foster self-esteem through routine and increased knowledge

Serve as motivator and driving force if you are pharmacy owner or branch manager

${ }^{\mathrm{a}} M R$ Medication review

highlight the role of technicians. This is consistent with previous studies showing that incorporation of technicians improves efficiency of MR and reduces barriers to implementation [1, 26-30]. In addition to the advice incorporate technicians, we could add information on how this can be done. For Germany, this means that technicians acquire patients for MR, assess the medical history, support in documentation, prepare interactionchecks and compile medication lists. Training in patient acquisition, adequate communication and education in process and benefits of MR is crucial. Providing feedback about findings during MR and documentation of the results in patients' healthrecords, visible for the team, are reasonable procedures as well. Training in all components of MR is a mayor aspect seen in our and in other studies [28, 31-34]. However, as stated in a study by Roberts et al., time for these trainings needs to be considered [34, 35]. A practical approach identified in our project is to acknowledge time for education and training as working hours. The training-sessions in the MR-process, patient- communication and -identification, took place during team-meetings and were offered repeatedly in all interviewed pharmacies in the PD-group.

How a team in a pharmacy performs is always influenced by and directly connected to the organisational structures of the pharmacy. Problems with time, staffing and inefficient workflow were also mentioned in the literature $[26,31$, 36-38]. Pharmacies in the PD-group changed the workflow, offered office hours to the AMTS-managers and restructured tasks. Execution of MR during free time at home seems to be relevant in Germany only. Nevertheless, due to changes 
in organisational structures all MR in the PD-group were conducted during working hours resulting in increased motivation to offer this service.

Besides changes in organisation, the particular service MR needs professionalisation itself. Successful implementation is based on integration of standardised material into the pharmacy-software [1, 37, 39-42]. Pharmacies in our study went a step further and made adaptions with their software providers, developed their own material and integrated a validated documentation template developed for Apo-AMTS. Usage of additional decision support systems and literature are well known approaches [35, 43, 44]. In contrast, the implementation of an external service to provide professional support run by the Pharmacists` Chamber in Westphalia-Lippe is unique.

To build a relationship with patients, AMTS-managers used personalised cards for appointments and included these appointments into the pharmacy-calendars. Provision of written results in a branded folder was resonable to demonstrate professionalism. Professionalisation of the service, which includes demonstrating a health professional attitude combined with well-defined organisational structures and comprises a definiton of criteria to identify patients for MR. Polymedication, experience of insecurity or side effects, recent discharge from hospital and living in nursing homes are widely accepted selection criteria also seen in our study. Labeling of eligible patients in the pharmacy's health-records was identified as useful for the selection process as an additional measure. Overdrawn expectations of patients, a lack of interest and incongruity between pharmacists` and patients` expectation often hamper the acceptance of MR which was also addressed by the interviewees of the CG [35, 37, 45]. Pharmacists from the PD-group overcome this barrier by starting to offer MR to patrons and nursing home residents. Doing so, they gained experience and routine in providing and executing this service. In addition, training in adequate patient-communication during team-meetings is identified as supportive.

Collaboration with practitioners was detected as difficult. Even if an older study from 1997 states that the relationship with practitioners has no influence on the execution of MR most publications and our results indicate that collaboration with GPs who are mainly adressed within the context or MR is still difficult [46]. Pharmacists are seen as shopkeepers who sell a service and not as patient-centered healthcare-professional and awareness of the role in community is lacking [47-53]. To optimise collaboration with GPs, it is of utmost importance to know each other in person and to increase awareness of the respective education, the fields of competence, working conditions and/or statutory duties $[49,54]$. Strategies to overcome these problems identified in our study were conducting one-on-one interviews with GPs prior to start the service with the aim to reach agreement about competencies, standard procedures and communication channels. We also recommend discussing first MR with practitioners in person to achieve positive experience with MR for both, pharmacist and GP. These approaches led to more acceptance and a consolidated relationship in other studies $[49,55,56]$. To foster relations, regular meetings eased collaboration.

In addition to these strategies, promotion of this service is of importance. This aspect was mentioned by Kotter but did not appear in literature later [45]. We identified useful measures like the use of branded promotion material (flyer, poster, video) and integration of social media like Facebook, Twitter and using the pharmacy`s homepage.

Remunaration of MR is often discussed as necessary for implementation. In Germany, patients usually pay for MR. Only in small projects as the $3 A$-project pharmacies receive remuneration. Results from our analysis as well as literature are ambiguous [26, 36, 57, 58]. Taking $80 €$ for one MR into account, which is close to an adequate payment, the low percentage of pharmacies conducting MR within the $3 \mathrm{~A}$ project $(57 \%)$ shows that remuneration is not a keyfactor for the implementation. Besides, when this fact is mentioned in both groups here, it should not be considered as a definite factor for success. Nevertheless, striving for remuneration in the future is reasonable.

Optimisation of the organisational factors is a prerequisite for implementation but a positive attitude towards MR, self-esteem of the pharmacists and readiness to take responsibility are crucial factors besides the willingness of pharmacy-owners/branch-managers to support and motivate their employees [35, 58-60]. We can add from our results that demonstration of pharmaceutical competencies in daily routine is the necessary basis to go to the next step and perform MR. Specialisation in particular topics like specific diseases increases self-esteem and confidence of the pharmacists and accelerates the process.

A limitation is that we did not weight these success factors. Therefore, a conclusion cannot be drawn in respect of the quantitative meaning of each of these factors. In addition, it is not possible to assess how these factors are linked together and the relation, respectively the mutual impact of the different factors on each other cannot be judged. This needs to be a matter for further studies. Conducting this study only in one region and with specially trained pharmacists is a possible limitation and needs to be considered if these results are transferred. Nevertheless, we assured by the sampling method that there was no difference between rural areas and larger cities. 


\section{Conclusion}

Using the PD-approach combined with a control-group, the results from this study enhance knowledge about strategies to improve implementation rates of MR, the success factors identified are robust, and credible. The promotion of widespread uptake of respective measures might foster the implementation of MR in community pharmacies. Further research is necessary to test the efficacy of these success factors in a larger sample.

Supplementary Information The online version contains supplementary material available at https://doi.org/10.1007/s11096-021-01315-1.

Acknowledgements I would like to thank all pharmacists and pharmacy technicians who participated in this study. Thanks to Ciarán Ryan for his help to translate the German phrases and finally, I want to thank Silke Gastine for her support to ensure that the language is used correctly.

Authors' contribution All authors contributed to the study conception and design. Material preparation, data collection and analysis where performed by Isabell Waltering. Isabell Waltering wrote the first draft of the manuscript and all authors commented on previous versions of the manuscript. All authors read and approved the final manuscript.

Funding Open Access funding enabled and organized by Projekt DEAL. This work was supported by the Apothekerkammer Westfalen-Lippe.

Data availability The Standards for Reporting Qualitative Research (SRQR) checklist was used to report this study. The datasets generated and analysed during the current study are available in German from the author on reasonable request.

Conflicts of interest The authors have no conflict of interest to declare.

Informed consent Informed consent was obtained from all individual participants included in the study.

Open Access This article is licensed under a Creative Commons Attribution 4.0 International License, which permits use, sharing, adaptation, distribution and reproduction in any medium or format, as long as you give appropriate credit to the original author(s) and the source, provide a link to the Creative Commons licence, and indicate if changes were made. The images or other third party material in this article are included in the article's Creative Commons licence, unless indicated otherwise in a credit line to the material. If material is not included in the article's Creative Commons licence and your intended use is not permitted by statutory regulation or exceeds the permitted use, you will need to obtain permission directly from the copyright holder. To view a copy of this licence, visit http://creativecommons.org/licenses/by/4.0/.

\section{References}

1. Turner K, Renfro C, Ferreri S, Roberts K, Pfeiffenberger T, Shea CM. Supporting community pharmacies with implementation of a web-based medication management application. Appl Clin
Inform. 2018;9(2):391-402. https://doi.org/10.1055/s-0038-16514 88.

2. Pérez-Jover V, Mira JJ, Carratala-Munuera C, Gil-Guillen VF, Basora J, López-Pineda A, et al. Inappropriate use of medication by elderly, polymedicated, or multipathological patients with chronic diseases. Int J Environ Res Public Health. 2018. https:// doi.org/10.3390/ijerph15020310.

3. Center for Medicare and Medicaid Services. 2018 Medicare Part D Medication Therapy Management (MTM) Programs. Fact Sheet 2018; August 20th, 2018 [cited 2021 Jun 19]. Available from: https://www.cms.gov/Medicare/Prescription-Drug-Coverage/ PrescriptionDrugCovContra/Downloads/CY2018-MTM-FactSheet.pdf.

4. Bulajeva A, Labberton L, Leikola S, Pohjanoksa-Mäntylä M, Geurts MME, de Gier JJ, et al. Medication review practices in European countries. Res Social Adm Pharm. 2014;10(5):731-40. https://doi.org/10.1016/j.sapharm.2014.02.005.

5. Australian Goverment-The Department of Health. Medication management reviews [cited 2020 Jun 03]. Available from: https:// www.health.gov.au/internet/main/publishing.nsf/Content/medic ation_management_reviews.htm.

6. Lee E, Braund R, Tordoff J. Examining the first year of Medicines Use Review services provided by pharmacists in New Zealand: 2008. N Z Med J. 2009;122(1293):3566.

7. Dolovich L, Consiglio G, MacKeigan L, Abrahamyan L, Pechlivanoglou $P$, Rac VE, et al. Uptake of the MedsCheck annual medication review service in Ontario community pharmacies between 2007 and 2013. Can Pharm J (Ott). 2016;149(5):293-302. https:// doi.org/10.1177/1715163516662670.

8. Bundesministerium der Justiz und für Verbraucherschutz. Verordnung über den Betrieb von Apotheken (Apothekenbetriebsordnung-ApBetrO) §1a Begriffsbestimmungen: Bundesministerium der Justiz und für Verbraucherschutz [cited 2021 Jun 19]. Available from: https://www.gesetze-im-internet.de/apobetro_1987/_ 1a.html.

9. Bundesvereinigung Deutscher Apothekerverbände ABDA. Grundsatzpapier zur Medikationsanalyse und zum Medikationsmanagement; 2014 [cited 2021 Jun 26]. Available from: https://www. abda.de/uploads/tx_news/Grundsatzpapier.pdf.

10. Waltering I, Schwalbe O, Hempel G. Serie AMTS: PraxisKonzept aus Westfalen-Lippe. PZ. 2013;43:22-3.

11. Griese-Mammen N, Hersberger KE, Messerli M, Leikola S, Horvat N, van Mil JWF, et al. PCNE definition of medication review: reaching agreement. Int J Clin Pharm. 2018;40(5):1199-208. https://doi.org/10.1007/s11096-018-0696-7.

12. Sternin J, Choo R. The power of positive deviancy. An effort to reduce malnutrition in Vietnam offers an important lesson about managing change. Harv Bus Rev. 2000;78(1):14-5.

13. The Positive Deviance Initiative. Basic Field Guide to the Positive Deviance Approach: Tufts University: Tufts University; 2010 [cited 2021 Jun 05]. Available from: https://static1.squarespace. com/static/5a1eeb26fe54ef288246a688/t/5a6eca16c83025f9bac2 eeff/1517210135326/FINALguide10072010.pdf.

14. Bradley EH, Curry LA, Ramanadhan S, Rowe L, Nembhard IM, Krumholz HM. Research in action: using positive deviance to improve quality of health care. Implement Sci. 2009;4:25. https:// doi.org/10.1186/1748-5908-4-25.

15. Baxter R, Taylor N, Kellar I, Lawton R. What methods are used to apply positive deviance within healthcare organisations? A systematic review. BMJ Qual Saf. 2016;25:190-201.

16. Ferracini FT, Marra AR, Schvartsman C, Dos Santos OFP, Victor EDS, Negrini NMM, et al. Using Positive Deviance to reduce medication errors in a tertiary care hospital. BMC Pharmacol Toxicol. 2016;17(1):36. https://doi.org/10.1186/s40360-016-0082-9.

17. Marra AR, Noritomi DT, Westheimer Cavalcante AJ, Sampaio Camargo TZ, Bortoleto RP, Durao Junior MS, et al. A multicenter 
study using positive deviance for improving hand hygiene compliance. Am J Infect Control. 2013;41(11):984-8. https://doi.org/10. 1016/j.ajic.2013.05.013.

18. Zaidi Z, Jaffery T, Shahid A, Moin S, Gilani A, Burdick W. Change in action: using positive deviance to improve student clinical performance. Adv Health Sci Educ Theory Pract. 2012;17(1):95-105. https://doi.org/10.1007/s10459-011-9301-8.

19. Bundesministerium fuer Gesundheit. Gesetzentwurf der Bundesregierung-Entwurf des Vierten Gesetzes zur Änderung arzneimittelrechtlicher und anderer Vorschriften.; 2016 [cited 2021 Jun 28]. Available from: https://www.bundesgesundheitsministerium. de/fileadmin/Dateien/3_Downloads/Gesetze_und_Verordnungen/ GuV/A/AMG-Novelle_GE.pdf.

20. Deutsche Forschungsgemeinschaft (DFG). DFG FörderungFragen zu Ethikantrag bei Interviewstudien [cited 2021 Jun 19]. Available from: (https://www.dfg.de/foerderung/faq/geistes_sozia lwissenschaften/.

21. Bundesinstitut fuer Arzneimittel und Medizinprodukte (BfArM). Klinische Prüfung-Bewertungsverfahren-Verordnung vom 12. Juli 2017; 2017 [cited 2021 Jun 19]. Available from: https://www. bfarm.de/DE/Arzneimittel/Arzneimittelzulassung/KlinischeP ruefung/Ethikkommissionen/_node.html.

22. Lamnek S. Qualitative Sozialforschung: Lehrbuch. 4., vollst. überarb. Aufl., [Nachdr.]. Weinheim: Beltz PVU; 2008ISBN 9783621275446. Available from: http://www.socialnet.de/rezen sionen/isbn.php?isbn=978-3-621-27544-6.

23. Bundesinstitut für Bau-, Stadt- und Raumforschung. Definition von Stadt- und Gemeindetypen nach Bundesamt für Bauwesen und Raumordnung; 2014 [cited 202106 19]. Available from: https://www.bbsr.bund.de/BBSR/DE/forschung/raumbeobac htung/Raumabgrenzungen/deutschland/gemeinden/StadtGemei ndetyp/StadtGemeindetyp.html.

24. Rose AJ, McCullough MB. A practical guide to using the positive deviance method in health services research. Health Serv Res. 2016. https://doi.org/10.1111/1475-6773.12524.

25. Kuckartz U. Qualitative Inhaltsanalyse. Methoden, Praxis, Computerunterstützung. 4. Auflage. Weinheim, Basel: Beltz Juventa; 2018. (Grundlagentexte Methoden) ISBN 9783779936824.

26. Bright DR, Lengel AJ, Powers MF. Pharmacists' perceptions of barriers to implementing medication therapy management and the role of pharmacy technicians in overcoming the barriers. Int J Pharm Technol Biotechnol. 2009;25(6):361-7. https://doi.org/ $10.1177 / 875512250902500603$.

27. Adeoye OA, Lake LM, Lourens SG, Morris RE, Snyder ME. What predicts medication therapy management completion rates? The role of community pharmacy staff characteristics and beliefs about medication therapy management. J Am Pharm Assoc. 2018;58:7-15.

28. Pattin AJ, Powers MF, Lengel AJ. Training community pharmacy technicians about their roles in the provision of medication therapy management services. J Pharm Technol. 2011;27:9-14.

29. Schommer JC, Planas LG, Johnson KA, Doucette WR. Pharmacist-provided medication therapy management (part 2): payer perspectives in 2007. J Am Pharm Assoc. 2008;48:478-86.

30. Chui MA, Mott DA, Maxwell L. A qualitative assessment of a community pharmacy cognitive pharmaceutical services program, using a work system approach. Res Social Adm Pharm. 2012;8(3):206-16. https://doi.org/10.1016/j.sapharm.2011.06. 001 .

31. Gernant SA. Optimizing the role of pharmacy technicians in patient care settings: nationally recognized, standardized training for technicians in pharmacist-delivered cognitive services. J Am Pharm Assoc. 2018;58:9-11.

32. Gernant SA, Nguyen M-O, Siddiqui S, Schneller M. Use of pharmacy technicians in elements of medication therapy management delivery: a systematic review. Res Soc Adm Pharm. 2017. https:// doi.org/10.1016/j.sapharm.2017.11.012.

33. Hart C, Price C, Graziose G, Grey J. A program using pharmacy technicians to collect medication histories in the emergency department. PT. 2015;40(1):56-61.

34. McGivney MS, Meyer SM, Duncan-Hewitt W, Hall DL, Goode J-VR, Smith RB. Medication therapy management: its relationship to patient counseling, disease management, and pharmaceutical care. J Am Pharm Assoc. 2003;47(5):620-8. https://doi.org/10. 1331/JAPhA.2007.06129.

35. Roberts AS, Benrimoj SI, Chen TF, Williams KA, Aslani P. Implementing cognitive services in community pharmacy: a review of facilitators used in practice change. Int J Pharm Pract. 2006;14(3):163-70. https://doi.org/10.1211/ijpp.14.3.0002.

36. Blake KB, Madhavan SS. Perceived barriers to provision of medication therapy management services (MTMS) and the likelihood of a pharmacist to work in a pharmacy that provides MTMS. Ann Pharmacother. 2010;44(3):424-31. https://doi.org/10.1345/aph. $1 \mathrm{M} 386$.

37. Yong FR, Garcia-Cardenas V, Williams KA, Charlie Benrimoj SI. Factors affecting community pharmacist work: a scoping review and thematic synthesis using role theory. Res Social Adm Pharm. 2019. https://doi.org/10.1016/j.sapharm.2019.05.001.

38. McCann L, Hughes CM, Adair CG, Cardwell C. Assessing job satisfaction and stress among pharmacists in Northern Ireland. Pharm World Sci. 2009;31(2):188-94. https://doi.org/10.1007/ s11096-008-9277-5.

39. Maddux MS, Dong BJ, Miller WA, et al. A vision of pharmacy`s future roles, responsibilities, and manpower needs in the United States. Pharmacotherapy. 2000;20:981-90.

40. Odedina FT, Segal R, Hepler C. Providing pharmaceutical care in community practice: differences between providers and non-providers of pharmaceutical care. J Soc Admin Pharm. 1995;12:170-80.

41. Nelson A, Zelnio RN, Beno CE. Clinical pharmaceutical service in retail practice II. Factors influencing the provision of services. Drug Intell Clin Pharm. 1984;18:992-6.

42. Doucette WRKY. An exploratory study of community pharmacy practice change. J Am Pharm Assoc. 2000;40:384-91.

43. Krska JVG. Perceived factors influencing the development of primary care-based pharmaceutical care in Scotland. Int J Pharm Pract. 2001;9:243-52.

44. Rovers JP, Currie JD. A practical guide to pharmaceutical care: A clinical skills primer. 3rd ed. Washington, D.C: American Pharmacists Association; 2007ISBN 9781582121048.

45. Kotter JP. Leading Change: Why Transformation Efforts Fail; 1995 [cited 2021 Jun 21]. Available from: https://hbr.org/1995/ 05/leading-change-why-transformation-efforts-fail-2.

46. Ventakataraman K, Madhavan S, Bone P. Barriers and facilitators to pharmaceutical care in rural community practice. J Soc Admin Pharm. 1997;14:208-19.

47. Patton SJ, Miller FA, Abrahamyan L, Rac VE. Expanding the clinical role of community pharmacy: a qualitative ethnographic study of medication reviews in Ontario. Canada Health Policy. 2018;122(3):256-62. https://doi.org/10.1016/j.healthpol.2017. 10.007.

48. Bryant LJM, Coster G, Gamble GD, McCormick RN. General practitioners' and pharmacists' perceptions of the role of community pharmacists in delivering clinical services. Res Soc Adm Pharm. 2009;5(4):347-62. https://doi.org/10.1016/j.sapha rm.2009.01.002.

49. Weissenborn M, Haefeli WE, Peters-Klimm F, Seidling HM. Interprofessional communication between community pharmacists and general practitioners: a qualitative study. Int $\mathbf{J}$ Clin Pharm. 2017;39(3):495-506. https://doi.org/10.1007/ s11096-017-0450-6. 
50. Urban R, Paloumpi E, Rana N, Morgan J. Communicating medication changes to community pharmacy post-discharge: the good, the bad, and the improvements. Int J Clin Pharm. 2013;35(5):81320. https://doi.org/10.1007/s11096-013-9813-9.

51. Roberts AS, Benrimoj SI, Chen TF, Williams KA, Aslani P. Implementing cognitiv services in community pharmacy: a review of facilitators used in practice changes. Int J Pharm Pract. 2006;14:163-70.

52. Rutter PR, Hunt AJ, Jones IF. Exploring the gap: community pharmacists' perceptions of their current role compared with their aspirations. Int J Pharm Pract. 2000;8(3):204-8. https://doi.org/ 10.1111/j.2042-7174.2000.tb01006.x.

53. Hughes CM, McCann S. Perceived interprofessional barriers between community pharmacists and general practitioners: a qualitative assessment. Br J Gen Pract. 2003;53(493):600-6.

54. Muijrers PEM, Knottnerus JA, Sijbrandij J, Janknegt R, Grol RPTM. Pharmacists in primary care Determinants of the careproviding function of Dutch community pharmacists in primary care. Pharm World Sci. 2004;26(5):256-62. https://doi.org/10. 1023/B:PHAR.0000042866.39002.d5.

55. Rose O, Richling I, Voigt K, Gottschall M, Köberlein-Neu J. Patient selection and general practitioners' perception of collaboration in medication review. Res Soc Adm Pharm. 2019;15(5):521-7. https://doi.org/10.1016/j.sapharm.2018.06. 019.

56. Pottie K, Farrell B, Haydt S, Dolovich L, Sellors C, Kennie N, et al. Integrating pharmacists into family practice teams: physicians' perspectives on collaborative care. Can Fam Physician. 2008;54(12):1714-1717.e5.
57. Koberlein-Neu J, Mennemann H, Hamacher S, Waltering I, Jaehde U, Schaffert C, et al. Interprofessional medication management in patients with multiple morbidities. Dtsch Arztebl Int. 2016;113(44):741-8. https://doi.org/10.3238/arztebl.2016.0741.

58. Stafford R, Thomas J, Payakachat N, Diemer T, Lang M, Kordsmeier B, et al. Using an array of implementation strategies to improve success rates of pharmacist-initiated medication therapy management services in community pharmacies. Res Soc Adm Pharm. 2017;13(5):938-46. https://doi.org/10.1016/j.sapharm. 2017.04.006.

59. Dunlop JA, Shaw JP. Community pharmacists' perspectives on pharmaceutical care implementation in New Zealand. Pharm World Sci. 2002;24(6):224-30. https://doi.org/10.1023/A:10215 26425458.

60. Ploeg J, Valaitis RK, Cleghorn L, Yous M-L, Gaber J, Agarwal G, et al. Perceptions of older adults in Ontario, Canada on the implementation and impact of a primary care programme, Health Teams Advancing Patient Experience: Strengthening Quality (Health TAPESTRY): a descriptive qualitative study. BMJ Open. 2019;9(6): e026257. https://doi.org/10.1136/bmjop en-2018-026257.

Publisher's Note Springer Nature remains neutral with regard to jurisdictional claims in published maps and institutional affiliations. 